\title{
HIV-1 immunogens and strategies to drive antibody responses towards neutralization breadth
}

\author{
Jelle van Schooten and Marit J. van Gils ${ }^{*}$ (i)
}

\begin{abstract}
Despite enormous efforts no HIV-1 vaccine has been developed that elicits broadly neutralizing antibodies (bNAbs) to protect against infection to date. The high antigenic diversity and dense N-linked glycan armor, which covers nearly the entire HIV-1 envelope protein (Env), are major roadblocks for the development of bNAbs by vaccination. In addition, the naive human antibody repertoire features a low frequency of exceptionally long heavy chain complementary determining regions (CDRH3s), which is a typical characteristic that many HIV-1 bNAbs use to penetrate the glycan armor. Native-like Env trimer immunogens can induce potent but strain-specific neutralizing antibody responses in animal models but how to overcome the many obstacles towards the development of bNAbs remains a challenge. Here, we review recent HIV-1 Env immunization studies and discuss strategies to guide strain-specific antibody responses towards neutralization breadth.
\end{abstract}

\section{Introduction}

The human immunodeficiency virus type 1 (HIV-1) continues to be a global health threat and the development of an effective vaccine is highly desirable to eradicate HIV/AIDS. Most existing viral vaccines work through the induction of neutralizing antibodies (NAbs) that block infection and/or viremia [1]. Despite enormous scientific progress since the discovery of HIV-1 as the causative agent of AIDS in the early 1980s, a safe and effective vaccine remains elusive. One of the greatest challenges of developing an effective vaccine with broad coverage is the extraordinary degree of genetic diversity within HIV-1 around the world and more specifically the high sequence variability in the HIV-1 envelope glycoprotein (Env) [2,3], the sole target for NAbs. Viruses of the HIV-1 group $M$ are responsible for the current HIV/AIDS pandemic and exhibit great viral diversity in their env gene [2,3]. The clades of group $M$ can differ by $25-35 \%$ in amino acid composition in Env, whereas

\footnotetext{
*Correspondence: M.J.vangils@amc.uva.nl

Department of Medical Microbiology, Amsterdam UMC, University

of Amsterdam, Location AMC, Meibergdreef 9, Room K3-105,

1105AZ Amsterdam, The Netherlands
}

variation within a clade is usually $15-20 \%$ [2-4]. Furthermore, Env contains many co-translationally attached $N$-linked glycans which shield the underlying protein surface from NAbs [5, 6]. In HIV-1 infected individuals, NAbs are produced against the Env of the transmitted/founder $(\mathrm{T} / \mathrm{F})$ virus within weeks to months after primary infection [7-11]. This initial antibody response is primarily strain-specific (autologous) and unable to cross-neutralize other genetically diverse heterologous HIV-1 isolates [8, 10-14]. The selective pressure exerted by the autologous antibody response drives viral evolution in HIV-1 infected individuals and causes the virus to escape from neutralization $[7,8,14-19]$. After several years of infection, in approximately $20-30 \%$ of HIV-1 infected individuals the autologous antibody response develops the ability to cross-neutralize a broad range of different (heterologous) viral strains [9, 12, 13, 20-23]. Moreover, one study even reports that sera from $50 \%$ of 205 chronic HIV-1 infected individuals were able to neutralize a wide panel of heterologous HIV-1 virus isolates [24]. This suggests that almost half of all HIV-1 infected individuals are capable of producing NAb responses with moderate to strong NAb breadth and potency. These $\mathrm{NAb}$ responses are likely to involve multiple monoclonal 
antibodies (mAbs) and maybe different specificities that together achieve broad serum neutralization. Studying HIV-1 specific NAb responses has led to the isolation and identification of broadly neutralizing antibodies (bNAbs), which have remarkable potency and cross-neutralizing activity against diverse HIV-1 clades worldwide, mostly by targeting highly conserved sites on Env, such as the CD4-binding site (CD4bs). Passive transfer studies with bNAbs in non-human primates have demonstrated effective protection against simian/human immunodeficiency virus (SHIV) [25-27]. Therefore, it is widely believed that vaccine-elicited bNAbs would effectively protect against HIV-1 infection in humans, but no vaccine has been developed that is able to do so. Here, we will review the recent developments of NAb responses induced by HIV-1 Env immunogens and discuss immunization strategies to drive the antibody response towards neutralization breadth.

\section{Vaccine-elicited autologous neutralizing antibody responses}

HIV-1 isolates are widely used to determine the ability of vaccine-elicited antibody responses to neutralize HIV-1 virus variants in vivo. These HIV-1 isolates can be categorized based on their neutralization sensitivity 'Tier' phenotype $[28,29]$, with Tier-1 viruses being highly sensitive to antibody-mediated neutralization. Tier-1 viruses include lab-adapted viruses and a small fraction of circulating strains, whereas Tier-2 viruses have a higher resistance profile and comprise the majority of circulating HIV-1 strains.

As Env is the only target for NAbs, a wide range of different Env immunogens have been developed to induce NAbs against HIV-1. A synthetic peptide consisting of a part of the V3 region of gp120 (subunit of HIV-1 Env) was among the first immunogens able to induce a NAb response against a Tier-1 virus in rhesus monkeys [30]. Since then, a tremendous amount of immunization studies have been conducted using various Env immunogens including peptides, epitope scaffolds, recombinant gp120 proteins and uncleaved Envs [31]. However, these immunogens primarily elicited NAb responses against Tier-1 viruses and only sporadically against more neutralization-resistant circulating Tier-2 viruses [32-44]. Most of the Env immunogens tested so far did not resemble the native Env structure and therefore elicited mAbs against epitopes which are not well exposed on primary Tier-2 isolates or are shielded by the quaternary structure of the viral Env spike [28, 45-48]. Moreover, electron microscopy studies have demonstrated that non-native Env immunogens elicit mAbs against the CD4bs with an angle of approach that prevents binding to native Env trimer [49]. In recent years, native-like trimers based on the SOSIP design and related designs have consistently induced autologous Tier-2 NAb responses in different animal models [50-56]. These native-like trimers differ from other non-native Env immunogens as they mimic the structure of Env on the surface of the virus correctly and display multiple bNAb epitopes in a similar manner as how these epitopes appear on the viron-associated spike. Nevertheless, these native-like HIV-1 Env immunogens are not yet able to induce strong bNAb responses.

To better understand the limited breadth of vaccineelicited NAbs, elaborate serological analyses have been performed and demonstrate that immunodominant strain-specific glycan holes on Env have been responsible for the narrow breadth of these mAbs [36, 43, 57-59]. The immunodominance of a breach in the glycan shield was first observed in immunization studies with viruslike particles (VLPs) expressing JR-FL Env trimers where $\mathrm{NAb}$ responses targeted a site lacking a highly conserved glycan at residue 197 [43]. The immunodominance of a glycan hole was also confirmed in immunization studies with native-like trimers based on the viral isolate BG505, termed BG505 SOSIP trimers [50, 58-62], through serum neutralization analysis and the isolation of $\mathrm{mAbs}$ [58]. Whether NAbs against strain-specific glycan holes can be broadened and eventually can develop into bNAbs remains to be determined.

\section{Vaccine-elicited heterologous neutralizing antibody responses}

Much can be learned from the few instances of Env induced heterologous NAbs in animal models. Understanding the factors that caused the heterologous response in these few animals might help develop strategies to drive $\mathrm{NAb}$ responses towards breadth in the majority of vaccinees. In some species such as cows and llamas, bNAbs against HIV-1 have been elicited by vaccination [63-65]. From llamas immunized with a mixture of recombinant trimeric gp140s from clades $\mathrm{A}$ and $\mathrm{BC}$, heavy chain-only antibodies were isolated with broad and potent neutralizing activity targeting the CD4bs $[64,65]$. Llamas produce heavy chain-only antibodies which are much smaller in size than conventional mAbs and can therefore contact regions on Env that are normally inaccessible for human mAbs because of the glycan shield and/or other steric constraints. In another study, cows immunized with BG505 SOSIP trimers rapidly developed broad and potent serum HIV-1 specific NAb responses [63]. The BG505 SOSIP trimer has failed, however, to elicit bNAbs in other animal models with repertoires that resemble the human antibody repertoire more closely $[50,54]$. Isolation and characterization of NAbs from these cows revealed that these NAbs contained ultralong third heavy chain 
complementary determining regions (CDRH3s) able to reach the CD4bs through the glycan shield. Cows generally have very long CDRH3s in their antibody repertoire with an average CDRH3 length of 26 amino acids and up to more than 70 amino acids $[63,66]$, whereas the average CDRH3 length in humans is approximately 13-15 amino acids [67, 68]. Very long CDRH3s are also a typical characteristic of human bNAbs and often necessary to penetrate the dense glycan shield. Thus, despite the glycan shield of HIV-1 Env, bNAbs can be elicited in cows and llamas because of the specific nature of their naive antibody repertoire. However, long CDRH3s are rare in the human antibody repertoire [69] and as a consequence fewer antibody precursors with the capacity to develop into bNAbs are present, making it less likely that humans will develop similar responses as observed in cows and llamas, unless innovative immunogen design strategies are developed to select for these rare precursors.

\section{Strategies to elicit heterologous NAb responses through vaccination}

To date, only a few immunogens have sporadically induced cross-NAbs against more neutralization-resistant Tier-2 viruses in commonly used animal models, such as guinea pigs, rabbits and macaques although these responses were generally weak and only occurred in very few animals [54, 70-79]. With the development of nativelike Env trimer proteins, autologous Tier-2 responses are now consistently induced in animal models, but these neutralizing responses primarily target immunodominant strain-specific holes in the glycan shield of Env and are therefore unable to neutralize heterologous viruses. Although strain-specific glycan holes can be considered as a "dead-end" for NAb responses, they can also be exploited as an "opportunity" to guide autologous NAb responses towards breadth. Many bNAbs are known to interact with $N$-linked glycans on Env [80] and there are studies suggesting that the development of bNAb lineages VRC01 and PGT121 may have been initiated by viruses lacking conserved glycans at positions 276 [81] and 137 [82], respectively. This data implies that glycandeleted immunogens may be useful to prime the immune response against a specific site of interest. Further immunizations using immunogens in which removed glycans are gradually restored might help the mAbs to tolerate the dense glycan shield of Env and develop neutralization breadth. Thus, to drive autologous responses towards heterologous NAbs, careful selection of HIV-1 Env immunogens and immunization strategies are required to guide the humoral response into the right direction (Fig. 1).

\section{Focusing on conserved epitopes}

One strategy to drive the antibody response towards the more conserved epitopes on Env is to restrain the exposure of off-target non-NAb epitopes such as the V3 loop and the base of soluble native-like trimers. Off-target epitopes may hamper the elicitation of bNAbs due to the hierarchy in immunodominance between non-NAb and (b)NAb epitopes [83]. B cells with undesired and high affinity non-NAbs may enter germinal centers and block antigen binding to lower affinity $\mathrm{B}$ cell clones that have the potential to develop into bNAbs [84, 85]. In addition, $B$ cells with high affinity non-NAbs will take up and present more antigen, receive more help from $\mathrm{T}$ follicular helper cells and will therefore outcompete the desired $\mathrm{B}$ cells with neutralizing potential [83].

Similar to the native Env spike, which fluctuates between closed and more open conformations, the SOSIP trimer is conformationally flexible $[47,61,86$, 87]. These partially open trimers display various non$\mathrm{NAb}$ epitopes such as the immunodominant V3 loop as well as CD4-induced and CD4bs-associated nonNAb epitopes. To limit the exposure of the V3 loop, the BG505 SOSIP trimer was stabilized in its pre-fusion state by a $\mathrm{bNAb}$ directed to the $\mathrm{V} 1 \mathrm{~V} 2$ region of the trimer, termed PGT145 [88]. Immunization of the BG505 SOSIP trimer in complex with the antigen-binding fragment of PGT145 reduced V3 reactivity in guinea pigs but did not improve autologous or heterologous NAb responses in these animals. Moreover, stabilized closed trimers have been designed to limit the exposure of undesired non$\mathrm{NAb}$ epitopes. When injected into rabbits and macaques, lower levels of V3-directed non-NAbs were induced by the stabilized trimers without affecting the autologous Tier-2 responses [52-54]. The exposure and immunogenicity of V3 non-NAb epitopes was even further decreased by either the insertion of two glycans in the V3 loop or by introducing hydrophobic mutations in the V3 region $[55,89,90]$. However, restricting the V3-loop antigenicity did not improve heterologous Tier- 2 responses [54]. This suggests that the elimination of a single immunodominant non-NAb epitope on Env may not be sufficient to re-direct the antibody response towards bNAb epitopes.

Soluble native-like trimers expose a region at the base of the trimer which is normally occluded by the viral membrane. The base of the trimer appears to be immunodominant in mice [91], rabbits [55, 92] and macaques [55] and mAbs elicited against this region are generally non-neutralizing since this epitope does not exist on membrane-embedded Env. The addition of glycans within and around the base of native-like trimers was able to block binding of these base-directed mAbs [55]. However, whether glycan masking also makes the base 


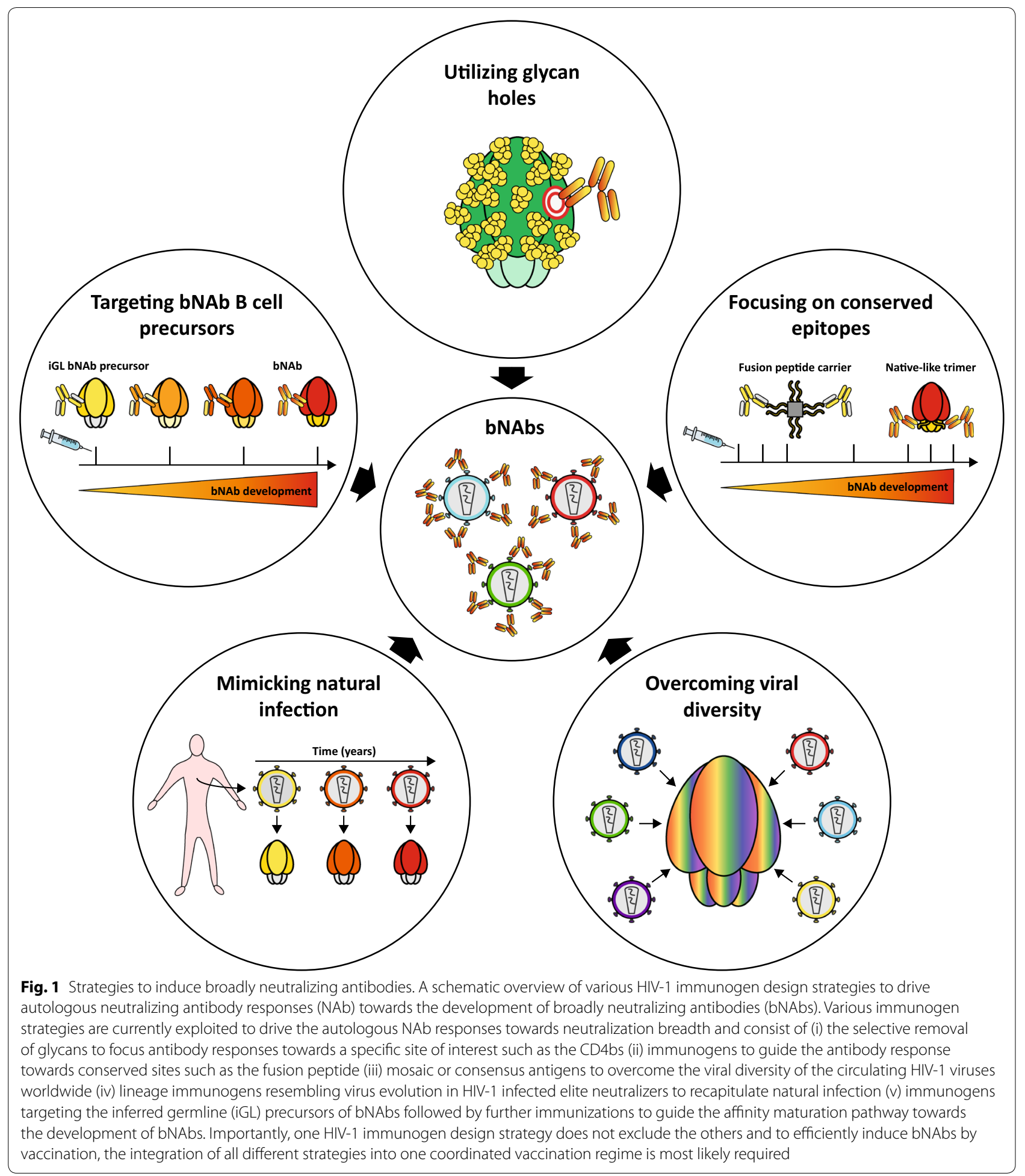

of the trimer less immunodominant in vivo still needs to be studied. A different strategy to mask the base of the trimer could be the presentation of trimers on nanoparticles to reduce off-target responses and increase autologous and heterologous NAb responses.
Another approach to develop antibody breadth is to concentrate the antibody response on conserved epitopes on Env such as the CD4bs or the fusion peptide. For the CD4bs, this can be achieved by creating holes in the glycan shield of Env to allow easier access for the mAbs to 
the underlying protein epitope and use these glycan holes here as an "opportunity" to drive NAb responses towards the CD4bs. The selective removal of glycans proximal to the CD4bs resulted in the induction of CD4bs-specific autologous NAb responses in guinea pigs and rhesus macaques [57]. These responses were, however, unable to neutralize the wild-type viral variants in which the glycans were present but it shows that it is possible to direct the antibody response towards a specific site of interest by creating an immunodominant glycan hole. Since CD4specific bNAbs isolated from HIV-1 infected individuals possess several unusual characteristics, optimized immunogen regimens are most likely needed, including the selective removal of glycans, to select for these rare mAbs followed by immunogens in which these glycans are gradually restored in order to develop antibody breadth.

Another attractive target for HIV-1 immunogen design is the Env fusion peptide, a critical component in viral entry as well as a target for bNAbs [93-95]. In a recent study, immunization with fusion peptide coupled to carrier proteins, followed by immunization with BG505 SOSIP trimers induced cross-clade Tier-2 NAbs in the majority of immunized mice [96]. Similar responses were observed in rhesus macaques and guinea pigs although only in a subset of the animals [96]. These data indicate that vaccines designed to focus on a conserved epitope, such as the fusion peptide, can increase the breadth of the immune response.

\section{Overcoming viral diversity}

To overcome the viral diversity of HIV-1, multiple distinct Env antigens are presumably needed to guide the humoral response towards neutralization breadth. However, the stimulation by multiple antigen variants and the influence on antibody affinity maturation is not well understood. Computational stimulations of a stochastic dynamic model of affinity maturation demonstrated that sequential immunization of antigen variants is favored over simultaneously administering a cocktail of those same antigens in eliciting bNAbs [97, 98]. However, two other computational models of affinity maturation suggest a role for immunizations with optimally designed antigen cocktails to induce breadth $[99,100]$. To test this in vivo, SOSIP trimers from clades $\mathrm{A}, \mathrm{B}$ and $\mathrm{C}$ were administered to rabbits either individually, sequentially or in a cocktail to evaluate the difference in efficacy between these strategies in eliciting NAbs $[62,101]$. Lower autologous NAb responses were generally generated in rabbits immunized with a combination of trimers from different clades when compared to monovalent immunizations [101]. Moreover, sequential immunization regimes did not increase heterologous or autologous NAb titers [62, 101]. In these studies, trimers from clades A, B and C were used which were most likely too genetically distinct to drive B cell maturation towards breadth. Therefore, sequential or combinatorial regimes based on more closely related env sequences are most likely needed to mimic the affinity maturation process that occurs during natural infection.

Another strategy to overcome the global HIV-1 diversity is the use of mosaic antigens. These antigens are computationally optimized to have a high proportion of immunological epitopes for improved coverage of the genetic diversity of HIV-1. In one study, guinea pigs were immunized with a clade A, B, C mosaic Env gp140 but only weak and sporadic autologous Tier-2 responses were elicited [102]. In a different study, adenovirus and poxvirus vector-based vaccines expressing HIV-1 mosaic antigens of Env, Gag and Pol demonstrated substantial protection against $\mathrm{SHIV}_{\mathrm{SF} 162 \mathrm{P} 3}$ in rhesus macaques [103]. Low levels of NAbs against SHIV $_{\text {SF162P3 }}$ were detected but NAbs against Tier-1 virus SF162 (Tier-1), Env-specific binding and nonneutralizing antibody-dependent cellular phagocytosis responses were correlated with protection [103]. As a follow-up study, both non-human primates and adults were primed with an adenovirus serotype 26 (Ad26)based mosaic HIV-1 vaccine and boosted with either an Ad26 or Modified Vaccinia Ankara (MVA) vector with a clade C Env gp140 [104]. Both immunization regimes induced Env-specific binding antibody responses, $\mathrm{T}$ cell responses and antibody-dependent cellular phagocytosis in non-human primates and humans. Moreover, these three parameters correlated with protection against repeated $\mathrm{SHIV}_{\mathrm{SF} 162 \mathrm{P} 3}$ challenges in non-human primates, but no Tier-2 NAbs were elicited.

A different approach to deal with the viral diversity of HIV-1 is the use of consensus Env immunogens which are based on HIV-1 sequences specifically designed to minimize the genetic distance between the circulating HIV-1 viruses. In one of these studies an oligomeric gp140 protein based on a group M consensus env gene (Con-S) was used to immunize guinea pigs and induced weakly cross-subtype NAbs against a subset of Tier-2 viruses $[72,73]$. When tested as a Con-S Env gp120 in macaques similar responses were observed [74]. Although weak and sporadic, these heterologous NAb responses suggest that using a consensus $\mathrm{M}$ env gene may have potential to induce heterologous responses and should be further exploited. Future studies will have to point out whether other mosaic or consensus Env immunogens are better at eliciting bNAb responses compared to immunogens consisting of natural sequences. 


\section{Mimicking natural infection}

Vaccine strategies using a combination of highly diverse viral isolates have only elicited autologous responses, as described above [62, 101]. However, during the affinity maturation process of bNAbs in infected individuals, B cells are exposed to antigen variants that are more closely related. Longitudinal studies of $\mathrm{HIV}-1 \mathrm{~T} / \mathrm{F}$ viruses and the co-evolving HIV-1 bNAb lineages have demonstrated that development of neutralization breadth relies on increasing viral Env diversity [17, 18, 23, 105]. One approach to recapitulate this co-evolutionary process is based on HIV-1 bNAbs and the natural longitudinal env sequences that have elicited them $[17,18]$, termed lineage immunogens.

In one antibody-virus co-evolution study, two different CD4bs bNAbs lineages ( $\mathrm{CH} 103$ and $\mathrm{CH} 235)$ were isolated from a HIV-1 infected individual CH505 [17, 106]. To elicit $\mathrm{CH} 103$ lineage-like mAbs, rhesus macaques were immunized with longitudinal CH505 Envs but the majority of the animals failed to generate autologous or heterologous Tier-2 neutralization [76, 107]. Only one out of eight immunized rhesus macaques developed NAbs against the autologous $\mathrm{CH} 505$ Tier-2 virus and various heterologous Tier-2 viruses [76]. Plasma neutralization activity was V1V2-glycan orientated and did not target the CD4bs. Similarly, V1V2-glycan but not CD4bs targeting NAbs were elicited in experiments with germline $\mathrm{CH} 103$ heavy-chain-only knock-in mice. These mice are subject to gene editing and rearrangements in their antibody repertoire which may explain why they developed NAbs against the V1/V2 glycan epitope and not the CD4bs [76]. Overall, these results demonstrate that eliciting CD4bs bNAbs remains difficult even with an Env that elicited such responses during natural infection. However, when rhesus macaques were immunized with a vectored-immunogen expressing $\mathrm{CH} 505$ T/F Envs, NAbs were indeed elicited against the CD4bs of the T/F virus [108]. A set of six CH505 Env immunogens have now been optimized and predicted to elicit both $\mathrm{CH} 103$ and CH235-like bNAbs lineages [105, 109], and clinical studies are underway to test whether this will be the case.

Approximately $1 \%$ of HIV-1 infected individuals generate NAb responses with remarkable breadth and potency against most viral subtypes [110]. These individuals are described as "elite neutralizers" and demonstrate that the human $B$ cell repertoire can overcome the extreme diversity of the circulating HIV-1 strains worldwide. Understanding why these exceptionally broad and potent responses only develop in these individuals, and more specifically which env sequences have induced these responses, can assist in the design of Env vaccines to elicit similar types of bNAbs. From one elite neutralizer CAP256, the V1V2-directed VRC26 lineage mAbs were isolated over time and the key viral events responsible for the development of neutralization breadth were determined [18, 23]. Based on these results, immunization strategies to elicit VRC26 lineage-like mAbs with longitudinally CAP256 Envs have been proposed using a prime to select for mAbs with long CDRH3s followed by three sequential boosts with various Envs that drove bNAb development in the CAP256 patient $[23,111]$.

\section{Targeting bNAb B cell precursors}

The majority of available recombinant Env proteins or HIV-1 isolates are incapable of interacting with the inferred germline (iGL) precursors of known bNAbs [112-115]. Research efforts have been made to specifically engineer HIV-1 immunogens with increased affinity to the iGL precursors of known bNAbs, in particular to elicit CD4bs bNAb lineages [116-120]. This "germlinetargeting" strategy aims to activate B cells expressing the unmutated precursor of a bNAb followed by further immunizations to guide the affinity maturation pathway towards the development of bNAbs. As the CD4bs is relatively well conserved among HIV-1 strains and because it is targeted in many HIV-1 infected individuals using genetically and structurally similar mAbs $[6,17$, 121-123], it is an attractive target for germline-targeting vaccines. In particular one class of CD4bs bNAbs, the VRC01-like bNAbs, is an appealing target because of the breadth and potency of its members. However, these bNAbs display several features such as a high degree of affinity maturation [124] and an unusually short (fiveresidue) light chain CDR3 [125] which might be hard to elicit by vaccination. Interestingly, a new CD4bs mAb, IOMA, was recently isolated which might be easier to elicit due to its relatively low rate of somatic hypermutation and normal-length light chain CDR3 [6]. Most of the CD4bs germline-targeting immunogens are based on gp120 monomers such as the engineered outer domain (eOD)-GT6/8 and 426c.TM4 $\Delta$ V1-V3 gp120-core proteins and generally involve deletions of glycan sites and/ or variable loops [116-119, 126]. When injected into knock-in mice engineered to express the iGL precursors of VRC01 or 3BNC60, these immunogens activated VRC01-class antibody responses better than regular recombinant Envs but neither the serum nor isolated mAbs possessed neutralizing activity [118, 127, 128]. Furthermore, priming with germline-targeting immunogens followed by sequential immunizations of various recombinant Envs, in which these glycans sites were gradually restored, generated NAb responses against HIV-1 isolates lacking a potential $N$-linked glycosylation site at position N276 but not when the N276 glycan was present $[129,130]$. As the N276 glycan is present in the majority of HIV-1 isolates, further research should point 
out if CD4bs-directed mAbs can be elicited that can tolerate the N276 glycan.

While these immunogens explicitly target iGL precursors of VRC01-like bNAbs, others have developed germline-targeting immunogens to elicit bNAbs targeting different epitopes on Env. Germline-targeting immunogens based on the BG505 SOSIP trimer, designed to specifically elicit PGT121-like responses, induced crossclade neutralization against heterologous Tier-2 viruses in the iGL PGT121 knock-in mice [77, 131]. In another study various SOSIP trimers with a glycan hole around the V2 apex were able to elicit V2-apex-focused autologous NAb responses in rabbits [78]. Interestingly, one rabbit developed NAb responses against five other heterologous Tier-2 viruses when four V2-apex targeting SOSIPS were given as a cocktail. Finally, a BG505 SOSIP trimer has been designed with binding properties to various iGL precursors of CD4bs as well as apex targeting bNAbs [120], termed BG505 SOSIP-GT1. Immunization studies in knock-in mice engineered to express the iGL precursors of VRC01 demonstrated that naive B cells with the right specificities were activated [120].

Although these data demonstrate that iGL B cell precursors of bNAbs can be activated in vivo, it is important to note that the exact germline sequences that bNAbs are derived from are generally unknown. As a result, many of the iGL precursors of bNAbs possess the CDRH3 of the mature antibody and may therefore not accurately represent the naïve $B$ cell precursors of bNAbs found in the human antibody repertoire. This is especially a problem for germline-targeting strategies aiming to elicit bNAbs that recognize Env completely through their CDRH3.

The iGL knock-in mice models used to assess the immunogenicity of the germline-targeting immunogens also contain the pre-fixed CDRH3 of mature bNAbs. Moreover, in these knock-in mice models the majority of the $\mathrm{B}$ cells express the heavy-chain and/or light chain of the iGL precursors of the desired bNAb. In humans, however, only a fraction of the $B$ cell population expresses the desired $B$ cell receptor and these B cells will need to compete for binding to Env with a majority of non-neutralizing B cells. Future studies in humans will have to reveal whether germline-targeting immunogens, based on the binding to these artificially reverted germline sequences, can activate $B$ cell precursors with the right specificities.

\section{Conclusions}

With the development of native-like trimers and optimal immunization regimes, autologous Tier-2 NAb responses are now consistently elicited in different animal models. However, these NAb responses predominantly target immunodominant holes in the glycan shield of Env due to the lack of glycosylation sites that are normally present in the majority of circulating HIV-1 strains. In many cases, these strain-specific glycan holes have led to a "dead-end" for the development of bNAbs and efforts to reduce offtarget epitopes on Env have been insufficient to focus the immune system towards more conserved epitopes and induce neutralization breadth. Therefore, glycan holes created by the selective removal of glycans near bNAb epitopes followed by gradually restoring them could serve as an "opportunity" to help the mAbs to tolerate the glycan shield of HIV-1 and focus the antibody response on conserved sites, such as the CD4bs and fusion peptide. Furthermore, co-evolution studies of bNAbs and virus have illuminated the complex nature of bNAb ontogeny, providing the field with valuable information on how to try to mimic this. One promising avenue is the germline-targeting strategy, with proof-of-concept experiments demonstrating that $\mathrm{B}$ cell precursors with the right specificities can be activated in vivo. However, to recapitulate natural infection by vaccination it most likely requires the integration of all different strategies reviewed here into one coordinated vaccination regime to efficiently induce heterologous NAbs. For example priming with germline targeting immunogens based on env sequences from patients that developed bNAb responses and boosting with lineage based immunogens from the same patient and/or immunogens representing consensus sequences. To determine the best route towards eliciting bNAb responses important knowledge gaps still need to be addressed. Current studies in humans will provide the field with valuable information as well as new insights how to proceed further which will hopefully lead to a vaccine that can protect against HIV-1.

\section{Authors' contributions \\ $J S$ and MJG wrote the review. Both authors read and approved the final manuscript.}

\section{Acknowledgements \\ M.J.G. is a recipient of an American Foundation for AIDS Research (amfAR) Krim Fellowship (109514-61-RKVA), as well as the 2017 AMC Fellowship. J.S. is a recipient of a 2017 AMC Ph.D. Scholarship. \\ Competing interests \\ The authors declare that they have no competing interests.}

\section{Publisher's Note}

Springer Nature remains neutral with regard to jurisdictional claims in published maps and institutional affiliations.

Received: 16 August 2018 Accepted: 16 November 2018 Published online: 26 November 2018

\section{References \\ 1. Plotkin SA. Correlates of protection induced by vaccination. Clin Vac- cine Immunol. 2010;17:1055-65. https://doi.org/10.1128/CVI.00131-10.}


2. Taylor BS, Sobieszczyk ME, McCutchan FE, Hammer SM. The challenge of HIV-1 subtype diversity. N Engl J Med. 2008;358:1590-602. https:// doi.org/10.1056/NEJMra0706737.

3. Lynch RM, Shen T, Gnanakaran S, Derdeyn CA. Appreciating HIV type 1 diversity: subtype differences in Env. AIDS Res Hum Retrovir. 2009;25:237-48. https://doi.org/10.1089/aid.2008.0219.

4. Gaschen B, Taylor J, Yusim K, Foley B, Gao F, Lang D, et al. Diversity considerations in HIV-1 vaccine selection. Science. 2002;296:2354-60.

5. Checkley MA, Luttge BG, Freed EO. HIV-1 envelope glycoprotein biosynthesis, trafficking, and incorporation. J Mol Biol. 2011;410:582-608. https ://doi.org/10.1016/j.jmb.2011.04.042.

6. Gristick HB, von Boehmer L, West AP Jr, Schamber M, Gazumyan A, Golijanin J, et al. Natively glycosylated HIV-1 Env structure reveals new mode for antibody recognition of the CD4-binding site. Nat Struct Mol Biol. 2016;23:906-15. https://doi.org/10.1038/nsmb.3291.

7. Arendrup M, Nielsen C, Hansen JE, Pedersen C, Mathiesen L, Nielsen JO. Autologous HIV-1 neutralizing antibodies: emergence of neutralizationresistant escape virus and subsequent development of escape virus neutralizing antibodies. J Acquir Immune Defic Syndr. 1992;5:303-7.

8. Richman DD, Wrin T, Little SJ, Petropoulos CJ. Rapid evolution of the neutralizing antibody response to HIV type 1 infection. Proc Natl Acad Sci USA. 2003;100:4144-9.

9. Deeks SG, Schweighardt B, Wrin T, Galovich J, Hoh R, Sinclair E, et al. Neutralizing antibody responses against autologous and heterologous viruses in acute versus chronic human immunodeficiency virus (HIV) infection: evidence for a constraint on the ability of HIV to completely evade neutralizing antibody responses. J Virol. 2006;80:6155-64. https:// doi.org/10.1128/JVI.00093-06.

10. Li B, Decker JM, Johnson RW, Bibollet-Ruche F, Wei X, Mulenga J, et al. Evidence for potent autologous neutralizing antibody titers and compact envelopes in early infection with subtype $\mathrm{C}$ human immunodeficiency virus type 1. J Virol. 2006;80:5211-8.

11. Gray ES, Moore PL, Choge IA, Decker JM, Bibollet-Ruche F, Li H, et al. Neutralizing antibody responses in acute human immunodeficiency virus type 1 subtype C infection. J Virol. 2007;81:6187-96. https://doi. org/10.1128/JVI.00239-07.

12. Bunnik EM, Pisas L, van Nuenen AC, Schuitemaker H. Autologous neutralizing humoral immunity and evolution of the viral envelope in the course of subtype B human immunodeficiency virus type 1 infection. J Virol. 2008:82:7932-41. https://doi.org/10.1128/JVI.00757-08.

13. Euler Z, van den Kerkhof TLGM, van Gils MJ, Burger JA, Edo-Matas D, Phung $\mathrm{P}$, et al. Longitudinal analysis of early HIV-1-specific neutralizing activity in an elite neutralizer and in five patients who developed cross-reactive neutralizing activity. J Virol. 2012;86:2045-55. https://doi. org/10.1128/JVI.06091-11.

14. Wei X, Decker JM, Wang S, Hui H, Kappes JC, Wu X, et al. Antibody neutralization and escape by HIV-1. Nature. 2003;422:307-12. https:// doi.org/10.1038/nature01470.

15. Wood N, Bhattacharya T, Keele BF, Giorgi E, Liu M, Gaschen B, et al. HIV evolution in early infection: selection pressures, patterns of insertion and deletion, and the impact of APOBEC. PLoS Pathog. 2009:5:e1000414. https://doi.org/10.1371/journal.ppat.1000414.

16. Rong R, Li B, Lynch RM, Haaland RE, Murphy MK, Mulenga J, et al. Escape from autologous neutralizing antibodies in acute/early subtype C HIV-1 infection requires multiple pathways. PLoS Pathog. 2009;5:e1000594. https://doi.org/10.1371/journal.ppat.1000594.

17. Liao H-X, Lynch R, Zhou T, Gao F, Alam SM, Boyd SD, et al. Co-evolution of a broadly neutralizing HIV-1 antibody and founder virus. Nature. 2013:496:469-76. https://doi.org/10.1038/nature12053.

18. Doria-Rose NA, Schramm CA, Gorman J, Moore PL, Bhiman JN, DeKosky BJ, et al. Developmental pathway for potent V1V2-directed HIV-neutralizing antibodies. Nature. 2014;509:55-62. https://doi.org/10.1038/natur e13036.

19. Moore PL, Ranchobe N, Lambson BE, Gray ES, Cave E, Abrahams $M R$, et al. Limited neutralizing antibody specificities drive neutralization escape in early HIV-1 subtype C infection. PLoS Pathog. 2009;5:e1000598.

20. Moog C, Fleury HJ, Pellegrin I, Kirn A, Aubertin AM. Autologous and heterologous neutralizing antibody responses following initial seroconversion in human immunodeficiency virus type 1 -infected individuals.
J Virol. 1997;71:3734-41. http://www.ncbi.nlm.nih.gov/pubmed/90946 48. Accessed 23 Feb 2018.

21. Wibmer CK, Bhiman JN, Gray ES, Tumba N, Abdool Karim SS, Williamson C, et al. Viral escape from HIV-1 neutralizing antibodies drives increased plasma neutralization breadth through sequential recognition of multiple epitopes and immunotypes. PLoS Pathog. 2013;9:e1003738. https:// doi.org/10.1371/journal.ppat.1003738.

22. van Gils MJ, Euler Z, Schweighardt B, Wrin T, Schuitemaker H. Prevalence of cross-reactive HIV-1-neutralizing activity in HIV-1-infected patients with rapid or slow disease progression. AIDS. 2009;23:2405-14. https:// doi.org/10.1097/QAD.0b013e32833243e7.

23. Bhiman JN, Anthony C, Doria-Rose NA, Karimanzira O, Schramm CA Khoza T, et al. Viral variants that initiate and drive maturation of V1V2directed HIV-1 broadly neutralizing antibodies. Nat Med. 2015;21:13326. https://doi.org/10.1038/nm.3963.

24. Hraber P, Seaman MS, Bailer RT, Mascola JR, Montefiori DC, Korber BT. Prevalence of broadly neutralizing antibody responses during chronic HIV-1 infection. AIDS. 2014;28:163-9.

25. Moldt B, Rakasz EG, Schultz N, Chan-Hui P-Y, Swiderek K, Weisgrau KL, et al. Highly potent HIV-specific antibody neutralization in vitro translates into effective protection against mucosal SHIV challenge in vivo. Proc Natl Acad Sci U S A. 2012;109:18921-5. https://doi.org/10.1073/ pnas.1214785109.

26. Hessell AJ, Rakasz EG, Poignard P, Hangartner L, Landucci G, Forthal DN, et al. Broadly neutralizing human anti-HIV antibody $2 \mathrm{G} 12$ is effective in protection against mucosal SHIV challenge even at low serum neutralizing titers. PLoS Pathog. 2009;5:e1000433.

27. Shingai M, Donau OK, Plishka RJ, Buckler-White A, Mascola JR, Nabel GJ, et al. Passive transfer of modest titers of potent and broadly neutralizing anti-HIV monoclonal antibodies block SHIV infection in macaques. J Exp Med. 2014;211:2061-74. https://doi.org/10.1084/jem.20132494.

28. Seaman MS, Janes H, Hawkins N, Grandpre LE, Devoy C, Giri A, et al. Tiered categorization of a diverse panel of HIV-1 Env pseudoviruses for assessment of neutralizing antibodies. J Virol. 2010;84:1439-52. https:// doi.org/10.1128/JVI.02108-09.

29. Montefiori DC, Roederer M, Morris L, Seaman MS. Neutralization tiers of HIV-1. Curr Opin HIV AIDS. 2017. https://doi.org/10.1097/coh.00000 00000000442.

30. Hart MK, Palker TJ, Matthews TJ, Langlois AJ, Lerche NW, Martin ME, et al. Synthetic peptides containing $T$ and $B$ cell epitopes from human immunodeficiency virus envelope gp120 induce anti-HIV proliferative responses and high titers of neutralizing antibodies in rhesus monkeys. J Immunol. 1990;145:2677-85. http://www.ncbi.nlm.nih.gov/pubme d/1698859. Accessed 2 Mar 2018.

31. Sliepen K, Sanders RW. HIV-1 envelope glycoprotein immunogens to induce broadly neutralizing antibodies. Expert Rev Vaccines. 2016;15:349-65. https://doi.org/10.1586/14760584.2016.1129905.

32. Wu L, Yang Z-Y, Xu L, Welcher B, Winfrey S, Shao Y, et al. Cross-clade recognition and neutralization by the $\mathrm{V} 3$ region from clade $\mathrm{C}$ human immunodeficiency virus-1 envelope. Vaccine. 2006;24:4995-5002. https ://doi.org/10.1016/j.vaccine.2006.03.083

33. Haynes BF, Ma B, Montefiori DC, Wrin T, Petropoulos CJ, Sutherland LL, et al. Analysis of HIV-1 subtype B third variable region peptide motifs for induction of neutralizing antibodies against HIV-1 primary isolates. Virology. 2006;345:44-55. https://doi.org/10.1016/j.virol.2005.08.042.

34. Wu X, Changela A, O'Dell S, Schmidt SD, Pancera M, Yang Y, et al. Immunotypes of a quaternary site of HIV-1 vulnerability and their recognition by antibodies. J Virol. 2011;85:4578-85. https://doi.org/10.1128/ JVI.02585-10.

35. Krachmarov C, Lai Z, Honnen WJ, Salomon A, Gorny MK, Zolla-Pazner S, et al. Characterization of structural features and diversity of variableregion determinants of related quaternary epitopes recognized by human and rhesus macaque monoclonal antibodies possessing unusually potent neutralizing activities. J Virol. 2011;85:10730-40. https://doi. org/10.1128/JVI.00365-11.

36. Bradley T, Fera D, Bhiman J, Eslamizar L, Lu X, Anasti K, et al. Structural constraints of vaccine-induced tier-2 autologous HIV neutralizing antibodies targeting the receptor-binding site. Cell Rep. 2016;14:43-54. https://doi.org/10.1016/j.celrep.2015.12.017.

37. Dennison SM, Sutherland LL, Jaeger FH, Anasti KM, Parks R, Stewart $S$, et al. Induction of antibodies in rhesus macaques that recognize 
a fusion-intermediate conformation of HIV-1 gp41. PLoS One. 2011;6:e27824.

38. Totrov M, Jiang X, Kong XP, Cohen S, Krachmarov C, Salomon A, et al. Structure-guided design and immunological characterization of immunogens presenting the HIV-1 gp 120 V3 loop on a CTB scaffold. Virology. 2010;405:513-23.

39. Qin Y, Banasik M, Kim SJ, Penn-Nicholson A, Habte HH, LaBranche C, et al. Eliciting neutralizing antibodies with gp120 outer domain constructs based on M-group consensus sequence. Virology. 2014;462-463:363-76.

40. Ingale J, Tran K, Kong L, Dey B, McKee K, SchiefW, et al. Hyperglycosylated stable core immunogens designed to present the CD4 binding site are preferentially recognized by broadly neutralizing antibodies. $J$ Virol. 2014:88:14002-16. https://doi.org/10.1128/JVI.02614-14.

41. Selvarajah S, Puffer B, Pantophlet R, Law M, Doms RW, Burton DR. Comparing antigenicity and immunogenicity of engineered gp 120. J Virol. 2005;79:12148-63. https://doi.org/10.1128/JVI.79.19.12148-12163.2005.

42. Li Y, Svehla K, Mathy NL, Voss G, Mascola JR, Wyatt R. Characterization of antibody responses elicited by human immunodeficiency virus type 1 primary isolate trimeric and monomeric envelope glycoproteins in selected adjuvants. JVirol. 2006;80:1414-26. https://doi.org/10.1128/ JVI.80.3.1414-1426.2006.

43. Crooks ET, Tong T, Chakrabarti B, Narayan K, Georgiev IS, Menis S, et al. Vaccine-elicited tier $2 \mathrm{HIV}-1$ neutralizing antibodies bind to quaternary epitopes involving glycan-deficient patches proximal to the CD4 binding site. PLoS Pathog. 2015;11:e1004932. https://doi.org/10.1371/journ al.ppat.1004932.

44. Robinson JE, Franco K, Elliott DH, Maher MJ, Reyna A, Montefiori DC, et al. Quaternary epitope specificities of anti-HIV-1 neutralizing antibodies generated in rhesus macaques infected by the simian/human immunodeficiency virus SHIVSF162P4. J Virol. 2010;84:3443-53. https:// doi.org/10.1128/JVI.02617-09.

45. Kwong PD, Doyle ML, Casper DJ, Cicala C, Leavitt SA, Majeed S, et al. HIV-1 evades antibody-mediated neutralization through conformational masking of receptor-binding sites. Nature. 2002;420:678-82.

46. Vancott TC, Polonis VR, Loomis LD, Michael NL, Nara PL, Birx DL. Differential role of $\mathrm{V} 3$-specific antibodies in neutralization assays involving primary and laboratory-adapted isolates of HIV type 1. AIDS Res Hum Retrovir. 1995;11:1379-91. https://doi.org/10.1089/aid.1995.11.1379.

47. Munro JB, Gorman J, Ma X, Zhou Z, Arthos J, Burton DR, et al. Conformational dynamics of single HIV-1 envelope trimers on the surface of native virions. Science. 2014;346:759-63. https://doi.org/10.1126/scien ce.1254426.

48. Yasmeen A, Ringe R, Derking R, Cupo A, Julien JP, Burton DR, et al. Differential binding of neutralizing and non-neutralizing antibodies to native-like soluble HIV-1 Env trimers, uncleaved Env proteins, and monomeric subunits. Retrovirology. 2014;11:41.

49. Tran K, Poulsen C, Guenaga J, de Val N, Wilson R, Sundling C, et al. Vaccine-elicited primate antibodies use a distinct approach to the HIV-1 primary receptor binding site informing vaccine redesign. Proc Natl Acad Sci. 2014;111:E738-47.

50. Sanders RW, van Gils MJ, Derking R, Sok D, Ketas TJ, Burger JA, et al. HIV-1 Vaccines. HIV-1 neutralizing antibodies induced by native-like envelope trimers. Science. 2015;349:aac4223. https://doi.org/10.1126/ science.aac4223.

51. Martinez-Murillo P, Tran K, Guenaga J, Lindgren G, Àdori M, Feng Y, et al. Particulate array of well-ordered HIV clade C Env trimers elicits neutralizing antibodies that display a unique V2 cap approach. Immunity. 2017:46:804-817.e7. https://doi.org/10.1016/.immuni.2017.04.021.

52. de Taeye SW, Ozorowski G, Torrents de la Peña A, Guttman M, Julien J-P, van den Kerkhof TLGM, et al. Immunogenicity of stabilized HIV-1 envelope trimers with reduced exposure of non-neutralizing epitopes. Cell. 2015;163:1702-15. https://doi.org/10.1016/j.cell.2015.11.056.

53. Havenar-Daughton C, Carnathan DG, Torrents de la Peña A, Pauthner $M$, Briney B, Reiss SM, et al. Direct probing of germinal center responses reveals immunological features and bottlenecks for neutralizing antibody responses to HIV Env trimer. Cell Rep. 2016;17:2195-209. https:// doi.org/10.1016/j.celrep.2016.10.085.

54. Pauthner M, Havenar-Daughton C, Sok D, Nkolola JP, Bastidas R, Boopathy $\mathrm{AV}$, et al. Elicitation of robust tier 2 neutralizing antibody responses in nonhuman primates by HIV envelope trimer immunization using optimized approaches. Immunity. 2017;46:1073-1088.e6. https://doi. org/10.1016/j.immuni.2017.05.007.

55. Kulp DW, Steichen JM, Pauthner M, Hu X, Schiffner T, Liguori A, et al. Structure-based design of native-like HIV-1 envelope trimers to silence non-neutralizing epitopes and eliminate CD4 binding. Nat Commun. 2017:8:1655. https://doi.org/10.1038/s41467-017-01549-6.

56. Feng $Y$, Tran K, Bale S, Kumar S, Guenaga J, Wilson R, et al. Thermostability of well-ordered HIV spikes correlates with the elicitation of autologous tier 2 neutralizing antibodies. PLoS Pathog. 2016;12:e1005767.

57. Zhou T, Doria-Rose NA, Cheng C, Stewart-Jones GBE, Chuang G-Y, Chambers M, et al. Quantification of the impact of the HIV-1-glycan shield on antibody elicitation. Cell Rep. 2017;19:719-32. https://doi. org/10.1016/j.celrep.2017.04.013.

58. McCoy LE, van Gils MJ, Ozorowski G, Messmer T, Briney B, Voss JE, et al. Holes in the glycan shield of the native HIV envelope are a target of trimer-elicited neutralizing antibodies. Cell Rep. 2016;16:2327-38. https ://doi.org/10.1016/j.celrep.2016.07.074.

59. Klasse PJ, Ketas TJ, Cottrell CA, Ozorowski G, Debnath G, Camara D, et al. Epitopes for neutralizing antibodies induced by HIV-1 envelope glycoprotein BG505 SOSIP trimers in rabbits and macaques. PLoS Pathog. 2018;14:e1006913. https://doi.org/10.1371/journal.ppat.1006913.

60. Sanders RW, Derking R, Cupo A, Julien J-P, Yasmeen A, de Val N, et al. A next-generation cleaved, soluble HIV-1 Env trimer, BG505 SOSIP.664 gp140, expresses multiple epitopes for broadly neutralizing but not non-neutralizing antibodies. PLoS Pathog. 2013;9:e1003618. https://doi. org/10.1371/journal.ppat.1003618.

61. Pugach P, Ozorowski G, Cupo A, Ringe R, Yasmeen A, de Val N, et al. A native-like SOSIP.664 trimer based on an HIV-1 subtype B env gene. J Virol. 2015;89:3380-95. https://doi.org/10.1128/JVI.03473-14.

62. Klasse PJ, LaBranche CC, Ketas TJ, Ozorowski G, Cupo A, Pugach P, et al. Sequential and simultaneous immunization of rabbits with HIV-1 envelope glycoprotein SOSIP.664 trimers from clades A, B and C. PLoS Pathog. 2016;12:e1005864.

63. Sok D, Le KM, Vadnais M, Saye-Francisco KL, Jardine JG, Torres JL, et al. Rapid elicitation of broadly neutralizing antibodies to HIV by immunization in cows. Nature. 2017;548:108-11. https://doi.org/10.1038/natur e23301.

64. McCoy LE, Quigley AF, Strokappe NM, Bulmer-Thomas B, Seaman MS, Mortier D, et al. Potent and broad neutralization of HIV-1 by a llama antibody elicited by immunization. J Exp Med. 2012;209:1091-103. https://doi.org/10.1084/jem.20112655.

65. McCoy LE, Rutten L, Frampton D, Anderson I, Granger L, Bashford-Rogers $\mathrm{R}$, et al. Molecular evolution of broadly neutralizing llama antibodies to the CD4-binding site of HIV-1. PLoS Pathog. 2014;10:e1004552. https ://doi.org/10.1371/journal.ppat.1004552.

66. de los Rios M, Criscitiello MF, Smider W. Structural and genetic diversity in antibody repertoires from diverse species. Curr Opin Struct Biol. 2015;33:27-41. https://doi.org/10.1016/j.sbi.2015.06.002.

67. Shi B, Ma L, He X, Wang X, Wang P, Zhou L, et al. Comparative analysis of human and mouse immunoglobulin variable heavy regions from IMGT/ LIGM-DB with IMGT/HighV-QUEST. Theor Biol Med Model. 2014;11:30. https://doi.org/10.1186/1742-4682-11-30.

68. Vigdorovich V, Oliver BG, Carbonetti S, Dambrauskas N, Lange MD, Yacoob C, et al. Repertoire comparison of the B-cell receptor-encoding loci in humans and rhesus macaques by next-generation sequencing. Clin Transl Immunol. 2016;5:e93. https://doi.org/10.1038/cti.2016.42.

69. Breden F, Lepik C, Longo NS, Montero M, Lipsky PE, Scott JK. Comparison of antibody repertoires produced by HIV-1 infection, other chronic and acute infections, and systemic autoimmune disease. PLOS ONE. 2011;6:e16857. https://doi.org/10.1371/journal.pone.0016857.

70. Townsley S, Mohamed Z, Guo W, McKenna J, Cleveland B, LaBranche $C$, et al. Induction of heterologous tier 2 HIV-1-neutralizing and crossreactive V1/N2-specific antibodies in rabbits by prime-boost immunization. JVirol. 2016:90:8644-60. https://doi.org/10.1128/JVI.00853-16.

71. Torrents de la Peña A, de Taeye SW, Sliepen K, LaBranche CC, Burger JA, Schermer EE, et al. Immunogenicity in rabbits of SOSIP trimers from clades A, B and C, given individually, sequentially or in combinations. J Virol. 2018. https://doi.org/10.1128/JVI.01957-17.

72. Liao HX, Sutherland LL, Xia SM, Brock ME, Scearce RM, Vanleeuwen S, et al. A group $\mathrm{M}$ consensus envelope glycoprotein induces antibodies 
that neutralize subsets of subtype B and C HIV-1 primary viruses. Virology. 2006;353:268-82.

73. Liao H-X, Tsao C-Y, Alam SM, Muldoon M, Vandergrift N, Ma B-J, et al. Antigenicity and immunogenicity of transmitted/founder, consensus, and chronic envelope glycoproteins of human immunodeficiency virus type 1. J Virol. 2013;87:4185-201. https://doi.org/10.1128/JVI.02297-12.

74. Hulot SL, Korber B, Giorgi EE, Vandergrift N, Saunders KO, Balachandran $\mathrm{H}$, et al. Comparison of immunogenicity in rhesus macaques of transmitted-founder, HIV-1 group M consensus, and trivalent mosaic envelope vaccines formulated as a DNA prime, NYVAC, and envelope protein boost. J Virol. 2015;89:6462-80. https://doi.org/10.1128/ JVI.00383-15.

75. Martinez P, Sundling C, O'Dell S, Mascola JR, Wyatt RT, Karlsson Hedestam GB. Primate immune responses to HIV-1 Env formulated in the saponin-based adjuvant AbISCO-100 in the presence or absence of TLR9 co-stimulation. Sci Rep. 2015;5:8925. https://doi.org/10.1038/srep0 8925 .

76. Saunders KO, Verkoczy LK, Jiang C, Zhang J, Parks R, Chen H, et al. Vaccine induction of heterologous tier 2 HIV-1 neutralizing antibodies in animal models. Cell Rep. 2017;21:3681-90. https://doi.org/10.1016/j. celrep.2017.12.028.

77. Escolano A, Steichen JM, Dosenovic P, Kulp DW, Golijanin J, Sok D, et al. Sequential immunization elicits broadly neutralizing anti-HIV-1 antibodies in lg knockin mice. Cell. 2016;166:1445-1458.e12. https:// doi.org/10.1016/j.cell.2016.07.030.

78. Voss JE, Andrabi R, McCoy LE, de Val N, Fuller RP, Messmer T, et al. Elicitation of neutralizing antibodies targeting the V2 apex of the HIV envelope trimer in a wild-type animal model. Cell Rep. 2017;21:222-35. https://doi.org/10.1016/j.celrep.2017.09.024.

79. Schiffner T, Pallesen J, Russell RA, Dodd J, de Val N, LaBranche CC, et al. Structural and immunologic correlates of chemically stabilized HIV-1 envelope glycoproteins. PLoS Pathog. 2018;14:e1006986. https://doi. org/10.1371/journal.ppat.1006986.

80. McCoy LE, Burton DR. Identification and specificity of broadly neutralizing antibodies against HIV. Immunol Rev. 2017;275:11-20

81. Lynch RM, Wong P, Tran L, O'Dell S, Nason MC, Li Y, et al. HIV-1 fitness cost associated with escape from the VRC01 class of CD4 binding site neutralizing antibodies. JVirol. 2015:89:4201-13.

82. Garces F, Lee JH, de Val N, Torrents de la Pena A, Kong L, Puchades C, et al. Affinity maturation of a potent family of HIV antibodies is primarily focused on accommodating or avoiding glycans. Immunity. 2015:43:1053-63.

83. Havenar-Daughton C, Lee JH, Crotty S. Tfh cells and HIV bnAbs, an immunodominance model of the HIV neutralizing antibody generation problem. Immunol Rev. 2017;275:49-61.

84. McGuire AT, Dreyer AM, Carbonetti S, Lippy A, Glenn J, Scheid JF, et al. Antigen modification regulates competition of broad and narrow neutralizing HIV antibodies. Science. 2014;346:1380-3.

85. Zhang Y, Meyer-Hermann M, George LA, Figge MT, Khan M, Goodall M, et al. Germinal center B cells govern their own fate via antibody feedback. J Exp Med. 2013;210:457-64. https://doi.org/10.1084/jem.20120 150.

86. Guttman M, Cupo A, Julien JP, Sanders RW, Wilson IA, Moore JP, et al. Antibody potency relates to the ability to recognize the closed, prefusion form of HIV Env. Nat Commun. 2015;6:6144.

87. Julien J-P, Lee JH, Ozorowski G, Hua Y, Torrents de la Peña A, de Taeye SW, et al. Design and structure of two HIV-1 clade C SOSIP.664 trimers that increase the arsenal of native-like Env immunogens. Proc Natl Acad Sci U S A. 2015;1 12:11947-52. https://doi.org/10.1073/pnas.15077 93112.

88. Cheng C, Pancera M, Bossert A, Schmidt SD, Chen R, Chen X, et al. Immunogenicity of a prefusion HIV-1-envelope trimer in complex with a quaternary-specific antibody. J Virol. 2015;90:2740-55.

89. de Taeye SW, de la Peña AT, Vecchione A, Scutigliani E, Sliepen K, Burger $J A$, et al. Stabilization of the gp1 20 V3 loop through hydrophobic interactions reduces the immunodominant $\mathrm{V} 3$-directed non-neutralizing response to HIV-1 envelope trimers. J Biol Chem. 2018;293:1688-701. https://doi.org/10.1074/jbc.RA117.000709.

90. Ringe RP, Ozorowski G, Rantalainen K, Struwe WB, Matthews K, Torres $\mathrm{J} \mathrm{L}$, et al. Reducing $\mathrm{V} 3$ antigenicity and immunogenicity on soluble, native-like HIV-1 env SOSIP trimers. J Virol. 2017. https://doi. org/10.1128/jvi.00677-17.

91. Hu JK, Crampton JC, Cupo A, Ketas T, van Gils MJ, Sliepen K, et al. Murine antibody responses to cleaved soluble HIV-1 envelope trimers are highly restricted in specificity. J Virol. 2015;89:10383-98.

92. Bianchi M, Turner HL, Nogal B, Cottrell CA, Oyen D, Pauthner M, et al. Electron-microscopy-based epitope mapping defines specificities of polyclonal antibodies elicited during HIV-1 BG505 envelope trimer immunization. Immunity. 2018:49(2):288-300.e8.

93. van Gils MJ, van den Kerkhof TLGM, Ozorowski G, Cottrell CA, Sok D, Pauthner M, et al. An HIV-1 antibody from an elite neutralizer implicates the fusion peptide as a site of vulnerability. Nat Microbiol. 2016;2:16199. https://doi.org/10.1038/nmicrobiol.2016.199.

94. Kong R, Xu K, Zhou T, Acharya P, Lemmin T, Liu K, et al. Fusion peptide of HIV-1 as a site of vulnerability to neutralizing antibody. Science. 2016;352:828-33. https://doi.org/10.1126/science.aae0474.

95. van Gils MJ, Sanders RW. Hitting HIV's Harpoon. Immunity. 2018;49:145. https://doi.org/10.1016/j.immuni.2018.07.003.

96. Xu K, Acharya P, Kong R, Cheng C, Chuang G-Y, Liu K, et al. Epitopebased vaccine design yields fusion peptide-directed antibodies that neutralize diverse strains of HIV-1. Nat Med. 2018;24(6):857-67. https:// doi.org/10.1038/s41591-018-0042-6.

97. Wang S, Mata-Fink J, Kriegsman B, Hanson M, Irvine DJ, Eisen HN, et al. Manipulating the selection forces during affinity maturation to generate cross-reactive HIV antibodies. Cell. 2015;160:785-97.

98. Wang S. Optimal sequential immunization can focus antibody responses against diversity loss and distraction. PLoS Comput Biol. 2017;13:e1005336.

99. Shaffer JS, Moore PL, Kardar M, Chakraborty AK. Optimal immunization cocktails can promote induction of broadly neutralizing Abs against highly mutable pathogens. Proc Natl Acad Sci. 2016;113:E7039-48. https://doi.org/10.1073/pnas.1614940113.

100. Luo S, Perelson AS. Competitive exclusion by autologous antibodies can prevent broad HIV-1 antibodies from arising. Proc Natl Acad Sci. 2015:112:11654-9. https://doi.org/10.1073/pnas.1505207112.

101. Torrents de la Peña A, de Taeye SW, Sliepen K, LaBranche CC, Burger JA, Schermer EE, et al. Immunogenicity in rabbits of SOSIP trimers from clades A, B and C, given individually, sequentially or in combinations. J Virol. 2018. https://doi.org/10.1128/jvi.01957-17.

102. Bricault CA, Kovacs JM, Badamchi-Zadeh A, McKee K, Shields JL, Gunn $\mathrm{BM}$, et al. Neutralizing antibody responses following long-term vaccination with HIV-1 env gp140 in Guinea pigs. JVirol. 2018. https://doi. org/10.1128/jvi.00369-18.

103. Barouch DH, Stephenson KE, Borducchi EN, Smith K, Stanley K, McNally $A G$, et al. Protective efficacy of a global HIV-1 mosaic vaccine against heterologous SHIV challenges in rhesus monkeys. Cell. 2013;155:531-9.

104. Barouch DH, Tomaka FL, Wegmann F, Stieh DJ, Alter G, Robb ML, et al. Evaluation of a mosaic HIV-1 vaccine in a multicentre, randomised, double-blind, placebo-controlled, phase 1/2a clinical trial (APPROACH) and in rhesus monkeys (NHP 13-19). Lancet. 2018;392:232-43. https:// doi.org/10.1016/S0140-6736(18)31364-3.

105. Bonsignori M, Zhou T, Sheng Z, Chen L, Gao F, Joyce MG, et al. Maturation pathway from germline to broad HIV-1 neutralizer of a CD4-mimic antibody. Cell. 2016;165:449-63.

106. Gao F, Bonsignori M, Liao HX, Kumar A, Xia SM, Lu X, et al. Cooperation of $B$ cell lineages in induction of HIV-1-broadly neutralizing antibodies. Cell. 2014:158:481-91.

107. Williams WB, Zhang J, Jiang C, Nicely NI, Fera D, Luo K, et al. Initiation of HIV neutralizing B cell lineages with sequential envelope immunizations. Nat Commun. 2017;8:1732. https://doi.org/10.1038/s41467-01701336-3.

108. McCurley NP, Domi A, Basu R, Saunders KO, LaBranche CC, Montefiori DC, et al. HIV transmitted/founder vaccines elicit autologous tier 2 neutralizing antibodies for the CD4 binding site. PLOS ONE. 2017;12:e0177863. https://doi.org/10.1371/journal.pone.0177863.

109. Bonsignori M, Liao HX, Gao F, Williams WB, Alam SM, Montefiori DC, et al. Antibody-virus co-evolution in HIV infection: paths for HIV vaccine development. Immunol Rev. 2017;275:145-60.

110. Simek MD, Rida W, Priddy FH, Pung P, Carrow E, Laufer DS, et al. Human immunodeficiency virus type 1 elite neutralizers: individuals with broad and potent neutralizing activity identified by using a high-throughput 
neutralization assay together with an analytical selection algorithm. J Virol. 2009;83:7337-48. https://doi.org/10.1128/JVI.00110-09.

111. Moore PL, Gorman J, Doria-Rose NA, Morris L. Ontogeny-based immunogens for the induction of V2-directed HIV broadly neutralizing antibodies. Immunol Rev. 2017;275:217-29.

112. Hoot S, McGuire AT, Cohen KW, Strong RK, Hangartner L, Klein F, et al. Recombinant HIV envelope proteins fail to engage germline versions of anti-CD4bs bNAbs. PLoS Pathog. 2013;9:e1003106.

113. McGuire AT, Glenn JA, Lippy A, Stamatatos L. Diverse recombinant HIV-1 Envs fail to activate $B$ cells expressing the germline $B$ cell receptors of the broadly neutralizing anti-HIV-1 antibodies PG9 and 447-52D. J Virol. 2014;88:2645-57. https://doi.org/10.1128/JVI.03228-13.

114. Xiao X, Chen W, Feng Y, Zhu Z, Prabakaran P, Wang Y, et al. Germlinelike predecessors of broadly neutralizing antibodies lack measurable binding to HIV-1 envelope glycoproteins: implications for evasion of immune responses and design of vaccine immunogens. Biochem Biophys Res Commun. 2009;390:404-9. https://doi.org/10.1016/j. bbrc.2009.09.029.

115. Sliepen K, Medina-Ramírez M, Yasmeen A, Moore JP, Klasse PJ, Sanders RW. Binding of inferred germline precursors of broadly neutralizing HIV-1 antibodies to native-like envelope trimers. Virology. 2015:486:116-20.

116. Jardine J, Julien J-P, Menis S, Ota T, Kalyuzhniy O, McGuire A, et al. Rational HIV immunogen design to target specific germline $B$ cell receptors. Science. 2013;340:711-6. https://doi.org/10.1126/scien ce. 1234150

117. McGuire AT, Hoot S, Dreyer AM, Lippy A, Stuart A, Cohen KW, et al. Engineering HIV envelope protein to activate germline B cell receptors of broadly neutralizing anti-CD4 binding site antibodies. J Exp Med. 2013;210:655-63.

118. McGuire AT, Gray MD, Dosenovic P, Gitlin AD, Freund NT, Petersen J, et al. Specifically modified Env immunogens activate B-cell precursors of broadly neutralizing HIV-1 antibodies in transgenic mice. Nat Commun. 2016;7:10618.

119. Jardine JG, Kulp DW, Havenar-Daughton C, Sarkar A, Briney B, Sok D, et al. HIV-1 broadly neutralizing antibody precursor $B$ cells revealed by germline-targeting immunogen. Science. 2016;351:1458-63. https:// doi.org/10.1126/science.aad9195.

120. Medina-Ramírez M, Garces F, Escolano A, Skog P, de Taeye SW, Del Moral-Sanchez I, et al. Design and crystal structure of a native-like
HIV-1 envelope trimer that engages multiple broadly neutralizing antibody precursors in vivo. J Exp Med. 2017;214:2573-90. https://doi. org/10.1084/jem.20161160.

121. Zhou T, Lynch RM, Chen L, Acharya P, Wu X, Doria-Rose NA, et al. Structural repertoire of HIV-1-neutralizing antibodies targeting the CD4 supersite in 14 donors. Cell. 2015;161:1280-92.

122. Scheid JF, Mouquet H, Ueberheide B, Diskin R, Klein F, Oliveira TYK et al. Sequence and structural convergence of broad and potent HIV antibodies that mimic CD4 binding. Science. 2011;333:1633-7.

123. Wu X, Zhou T, Zhu J, Zhang B, Georgiev I, Wang C, et al. Focused evolution of HIV-1 neutralizing antibodies revealed by structures and deep sequencing. Science. 2011;333:1593-602.

124. Kwong PD, Mascola JR. Human antibodies that neutralize HIV-1: identification, structures, and B cell ontogenies. Immunity. 2012;37:412-25.

125. West AP, Diskin R, Nussenzweig MC, Bjorkman PJ, Bjorkman PJ. Structural basis for germ-line gene usage of a potent class of antibodies targeting the CD4-binding site of HIV-1 gp120. Proc Natl Acad Sci U S A. 2012;109:E2083-90

126. Duan H, Chen X, Boyington JC, Alt FW, Kwong PD, Mascola JR. Glycan masking focuses immune responses to the HIV-1 CD4-binding site and enhances elicitation of VRC01-class precursor antibodies. Immunity. 2018;49(2):301-311.e5.

127. Dosenovic P, von Boehmer L, Escolano A, Jardine J, Freund NT, Gitlin AD, et al. Immunization for HIV-1 broadly neutralizing antibodies in human Ig knockin mice. Cell. 2015;161:1505-15. https://doi.org/10.1016/j. cell.2015.06.003.

128. Jardine JG, Ota T, Sok D, Pauthner M, Kulp DW, Kalyuzhniy O, et al. Priming a broadly neutralizing antibody response to HIV-1 using a germline-targeting immunogen. Science. 2015;349:156-61. https://doi. org/10.1126/science.aac5894.

129. Tian M, Cheng C, Chen X, Duan H, Cheng HL, Dao M, et al. Induction of HIV neutralizing antibody lineages in mice with diverse precursor repertoires. Cell. 2016;166:1471-1484.e18.

130. Briney B, Sok D, Jardine JG, Kulp DW, Skog P, Menis S, et al. Tailored immunogens direct affinity maturation toward HIV neutralizing antibodies. Cell. 2016;166:1459-1470.e11.

131. Steichen JM, Kulp DW, Tokatlian T, Escolano A, Dosenovic P, Stanfield RL, et al. HIV vaccine design to target germline precursors of glycandependent broadly neutralizing antibodies. Immunity. 2016;45:483-96.
Ready to submit your research? Choose BMC and benefit from:

- fast, convenient online submission

- thorough peer review by experienced researchers in your field

- rapid publication on acceptance

- support for research data, including large and complex data types

- gold Open Access which fosters wider collaboration and increased citations

- maximum visibility for your research: over $100 \mathrm{M}$ website views per year

At BMC, research is always in progress.

Learn more biomedcentral.com/submissions 